\title{
Increased appendicularian zooplankton alter carbon cycling under warmer more acidified ocean conditions
}

\author{
Monika Winder, ${ }^{1 *}$ Jean-Marie Bouquet, ${ }^{2,3}$ J. Rafael Bermúdez, ${ }^{4,5}$ Stella A. Berger, ${ }^{2,6,7}$ Thomas Hansen, ${ }^{4}$ \\ Jay Brandes, ${ }^{6}$ Andrey F. Sazhin, ${ }^{8}$ Jens C. Nejstgaard, ${ }^{6,7,9}$ Ulf Båmstedt, ${ }^{10}$ Hans H. Jakobsen, ${ }^{11}$ \\ Jörg Dutz, ${ }^{12}$ Marc E. Frischer, ${ }^{6}$ Christofer Troedsson, ${ }^{9}$ Eric M. Thompson ${ }^{2,3,9}$ \\ ${ }^{1}$ Department of Ecology, Environment and Plant Sciences, Stockholm University, Sweden \\ ${ }^{2}$ Department of Biology, University of Bergen, Bergen, Norway \\ ${ }^{3}$ Sars International Centre for Marine Molecular Biology, University of Bergen, Bergen, Norway \\ ${ }^{4}$ Helmholtz Centre for Ocean Research Kiel (GEOMAR), Kiel, Germany \\ ${ }^{5}$ Facultad de Ingeniería Marítima, Ciencias Biológicas, Oceánicas y Recursos Naturales, Escuela Superior Politécnica del \\ Litoral, ESPOL, Guayaquil, Ecuador \\ ${ }^{6}$ Skidaway Institute of Oceanography, University of Georgia, Savannah, Georgia \\ ${ }^{7}$ Department of Experimental Limnology, Leibniz-Institute of Freshwater Ecology and Inland Fisheries (IGB), \\ Stechlin, Germany \\ ${ }^{8}$ P. P. Shirshov Institute of Oceanology RAS, Moscow, Russia \\ ${ }^{9}$ Uni Research Environment, Uni Research AS, Bergen, Norway \\ ${ }^{10}$ Department of Ecology and Environmental Sciences, Umeå University, Umeå, Sweden \\ ${ }^{11}$ Department of Bioscience, Aarhus University, Roskilde, Denmark \\ ${ }^{12}$ Leibniz Institute for Baltic Sea Research Warnemünde, Rostock, Germany
}

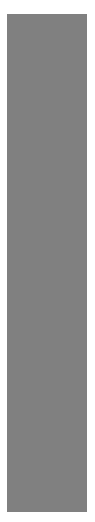

\begin{abstract}
Anthropogenic atmospheric loading of $\mathrm{CO}_{2}$ raises concerns about combined effects of increasing ocean temperature and acidification, on biological processes. In particular, the response of appendicularian zooplankton to climate change may have significant ecosystem implications as they can alter biogeochemical cycling compared to classical copepod dominated food webs. However, the response of appendicularians to multiple climate drivers and effect on carbon cycling are still not well understood. Here, we investigated how gelatinous zooplankton (appendicularians) affect carbon cycling of marine food webs under conditions predicted by future climate scenarios. Appendicularians performed well in warmer conditions and benefited from low $\mathrm{pH}$ levels, which in turn altered the direction of carbon flow. Increased appendicularians removed particles from the water column that might otherwise nourish copepods by increasing carbon transport to depth from continuous discarding of filtration houses and fecal pellets. This helps to remove $\mathrm{CO}_{2}$ from the atmosphere, and may also have fisheries implications.
\end{abstract}

Many of the world's marine ecosystems are impacted by combined effects of climate change and large-scale reorganization of community structure resulting from human activities such as increasing greenhouse gas emission, overfishing, nutrient loading, and habitat modification (Estes et al. 2011). Two of the most significant climate parameters that have far reaching consequences for marine ecosystems are increasing temperature and concentrations of atmospheric $\mathrm{CO}_{2}$ (Riebesell and Gattuso 2015), the latter reducing ocean

*Correspondence: monika.winder@su.se

Additional Supporting Information may be found in the online version of this article.
$\mathrm{pH}$ and leading to ocean acidification (IPCC 2014). Effects on ecosystem functioning largely depend on the response of organisms, which can lead to altered community structure and modified carbon cycling (Bermudez et al. 2016). Gelatinous zooplankton (e.g., jellyfish and appendicularians) play an important role in global biogeochemical cycles as they have high grazing rates and contribute to organic carbon export from the ocean surface to the sea bottom (Vargas et al. 2002; Lebrato et al. 2013). Yet, it is uncertain how the abundance and frequency of occurrence of these organisms are affected as a consequence of climate change (Richardson et al. 2009; Condon et al. 2013; Troedsson et al. 2013). An increase in gelatinous zooplankton is expected to profoundly affect plankton community structure and may modulate climate 
effects through altered competitive and trophic interactions, potentially affecting ecosystem functioning (Condon et al. 2011). However, these predictions have not been empirically tested in systems that contain multiple trophic levels and climate stressors. Here, we test the response of gelatinous zooplankton by using appendicularians as model organisms.

Zooplankton provide an essential ecosystem service through the transfer of energy and nutrients from primary producers to fish that are required to maintain the productivity of marine systems. Increasing dominance of gelatinous zooplankton has important implications for marine ecosystems by changing the direction of organic carbon flow compared to the classical food web dominated by copepods (Alldredge 2000; Condon et al. 2011). Copepods and gelatinous filter feeding appendicularians are important ubiquitous members of the pelagic ocean community (Deibel 1998; Vargas et al. 2002) with different functional roles (Gorsky and Fenaux 1998; Vargas et al. 2002; Stemmann et al. 2008). Copepods mediate a major trophic carbon pathway from microbial-sized organisms $(>5-10 \mu \mathrm{m})$ including phytoplankton and heterotrophic protists to fish. Through production of dense fecal pellets and vertical migration, they also contribute to carbon sedimentation (Stukel et al. 2013). Although less studied, appendicularians (planktonic tunicates) are known to be consumed by larger predators and a limited number of fish larvae (Gorsky and Fenaux 1998), and are efficient consumers of smaller nano- $(<10 \mu \mathrm{m})$ and pico$(<2 \mu \mathrm{m})$ plankton-sized particles (Gorsky et al. 1999; Sommer and Stibor 2002). They are also important producers of large sinking aggregates through the continuous release of filtering structures, called "houses" used for feeding. These gelatinous houses are frequently discarded after clogging and as animals grow (Flood and Deibel 1998), and combined with the concentrated prey particles and fecal pellets, these organic aggregates constitute a large fraction to global vertical carbon flux from the euphotic layer to the seafloor (Vargas et al. 2002; Alldredge 2005). Consequently, the structure of the zooplankton community composition has important implications for ocean carbon processes and their response to climate warming and ocean acidification will differentially affect ecosystem functioning. A shift toward gelatinous plankton, such as appendicularians may alter the flow of carbon through the food web, yet our current understanding of appendicularian responses to climate changes and their effects on carbon cycling is limited, compared to crustacean zooplankton. A previous mesocosm experiment suggested that the appendicularian Oikopleura dioica can tolerate elevated $p \mathrm{CO}_{2}$ levels (Troedsson et al. 2013). The set-up of the previous experiment did, however, not allow differentiating whether the response of appendicularians was due to $\mathrm{pH}$ reduction or an altered response to more alkaline conditions during the stimulated phytoplankton bloom. The previous experiment was also not designed to test the effects of appendicularians under natural and future ocean conditions on carbon cycling, as it did not include treatments lacking appendicularian addition.

To understand how future oceans will respond to climate change in combination with altered consumer populations, we utilized mesocosms (large seawater enclosures) with a natural coastal plankton community and investigated the effects of increased temperature, ocean acidification and abundance of appendicularians on plankton biomass, production and carbon cycling. Plankton dynamics and carbon processes were observed over the phytoplankton bloom and postbloom period. Our results highlight the importance of multi-trophic analysis to understand consequences of climate change on ecosystem functioning.

\section{Material and methods}

\section{Mesocosm setup and manipulation}

Coastal North Sea seawater from the Raunefjord, southern Norway containing the natural spring (June 2011) phytoand zooplankton community was pumped into 12 landbased mesocosms of $2500 \mathrm{~L}$ volume each $(1.5 \mathrm{~m}$ diameter, $1.5 \mathrm{~m}$ high). The mesocosms were made of white glass fiber tank open to the air. We compared how predictions by the year 2100 (IPCC 2014) of a $p \mathrm{CO}_{2}$ level of $1000 \mu \mathrm{atm}$ (realized mean values of $p \mathrm{CO}_{2} 818 \mu \mathrm{atm}, \mathrm{pH} 7.7 \pm 0.04$, temperature $14.6 \pm 0.7^{\circ} \mathrm{C}$ ) and a temperature increase of $2.6^{\circ} \mathrm{C}$ differ from ambient conditions of $400 \mu \mathrm{atm}$ (realized mean values of $\mathrm{pCO}_{2} 336 \mu \mathrm{atm}, \mathrm{pH} 8.02 \pm 0.08$, temperature $12.0 \pm 0.7^{\circ} \mathrm{C}$ ) at different abundance levels of the appendicularian $O$. dioica (Fig. 1 and Supporting Information Fig. S1). Examination of multiple stressors in large experimental units allowed two replicates with the following manipulations: low temperature and low $p \mathrm{CO}_{2}$ (Tl-Cl), low temperature and high $p \mathrm{CO}_{2}$ (Tl-Ch), high temperature and high $p \mathrm{CO}_{2}$ (Th-Ch), each with and without appendicularian (A) addition. The mesocosms were submerged in three larger holding tanks with four mesocosms each to maintain temperature control. All three holding tanks received continuous water from the fjord to maintain ambient temperature, while in one of the holding tanks the temperature was gradually increased by $2.6^{\circ} \mathrm{C}$ using a commercial pool heating device consisting of a $6 \mathrm{~kW}$ electric heating Titanium unit (Pahlén Norge AS, ref 141601T01), a circulation pump (Astral Sena ref 25463 0,74 kW, 50 $\mathrm{Hz}, 230 \mathrm{~V}$, mono phase, mounted on a $50 \mathrm{~mm}$ PVC tube) and a SAAS A/S temperature regulation system, Oslo. Regulation of $\mathrm{pH}$ was achieved by bubbling of $\mathrm{CO}_{2}$-enriched air at near ambient $(6 \times 400 \mu \mathrm{atm})$ and predicted $p \mathrm{CO}_{2}$ levels at $2100(6 \times 1000 \mu \mathrm{atm})$. Each mesocosm was gently mixed twice a day as previously described (Troedsson et al. 2013). This manipulation minimized destruction of sensitive plankton.

Nutrients were added to all mesocosms to stimulate a phytoplankton bloom at the beginning of the experiment using the following concentrations; $8 \mathrm{mM} \mathrm{NaNO}_{3}, 0.5 \mathrm{mM} \mathrm{K}_{2} \mathrm{HPO}_{4}$, and $5 \mathrm{mM} \mathrm{Na} \mathrm{NiO}_{3}$, resulting in targeted concentrations 


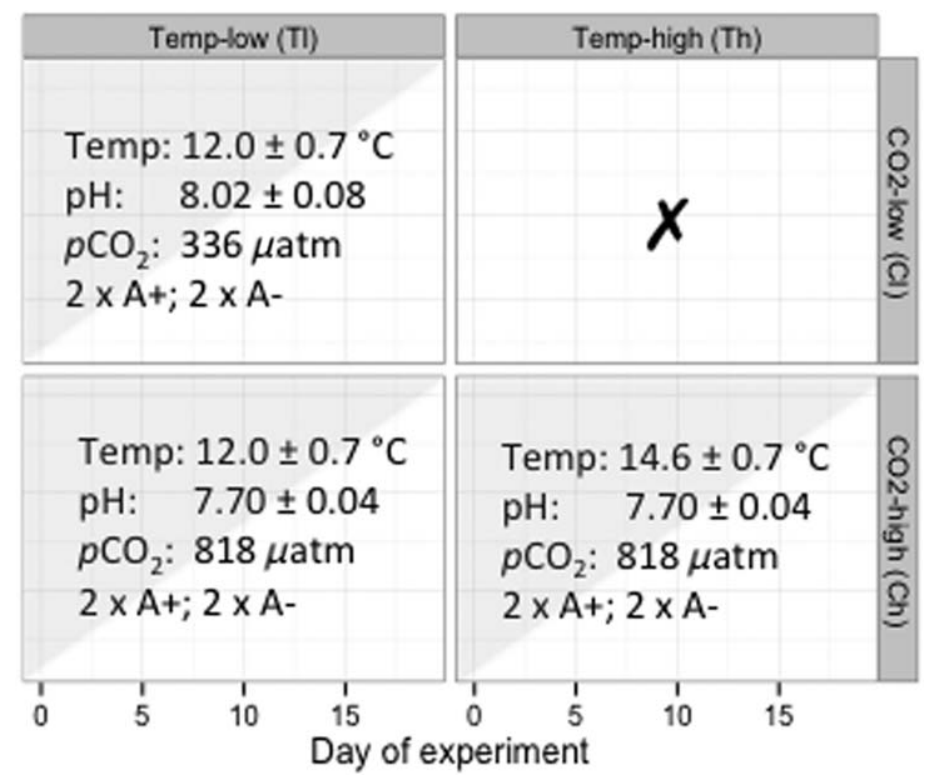

Fig. 1. Mesocosm experimental setup and measured mean $( \pm \mathrm{SD})$ temperature $(\mathrm{Temp}), \mathrm{pH}$, and $p \mathrm{CO}_{2}$ levels over the experimental period. All 12 mesocosms received nutrient addition; the appendicularian $\mathrm{O}$. dioica was added to two mesocosm of each treatment at the beginning of the experiment, indicated by the shaded area. Treatments: Temp-low ( $\mathrm{Tl})$, Temp-high (Th), $\mathrm{CO}_{2}$-low $(\mathrm{Cl}), \mathrm{CO}_{2}$-high ( $\left.\mathrm{Ch}\right)$, addition and no addition of the appendicularian $\mathrm{O}$. dioica (A+ and $\mathrm{A}-$, respectively).

$\left(\mu \mathrm{g} \mathrm{L}^{-1}\right)$ of $133.8 \mathrm{NO}_{3}, 8.8 \mathrm{PO}_{4}$, and $160.1 \mathrm{Si}$. The appendicularian $O$. dioica (synchronized day 1 stage) from a stock culture was added on day 0 to half of the mesocosms of each treatment (except the control) at a density of 10 ind. $\mathrm{L}^{-1}$. An immediate mortality within the first $24 \mathrm{~h}$ led to a mean starting density of 3.2 ind. $\mathrm{L}^{-1}$ at day 1 . Appendicularian starting concentrations in mesocosms without $O$. dioica additions were very low to undetectable in samples, and the community appeared to some extent at later sampling points in these mesocosms through spawning of the very limited initial individuals (average fecundity, $\sim 300$ eggs per female). The starting copepod community was dominated by immature stages of cyclopoid and calanoid species. Labeled ${ }^{13} \mathrm{C}$ $\mathrm{NaHCO}_{3}$ was added to mesocosms on day 0 to $2.3 \mu \mathrm{mol}$ $\mathrm{kg}^{-1}$, corresponding to about $0.1 \%$ of total dissolved inorganic carbon (DIC) to estimate carbon uptake and phytoplankton taxon-specific growth rates from fatty acid stable isotope measurements. Total incubation time for the experiment was $17 \mathrm{~d}$. A detailed description of the experimental system has been previously described (Calbet et al. 2014).

\section{Sampling and sample analysis}

Temperature and $\mathrm{pH}$ (NBS scale) were monitored twice a day using a WTW Multi 3420 equipped with a WTW Sentix $980 \mathrm{pH}$ probe. Before sampling, each mesocosm was gently stirred to homogenize plankton for quantitative sampling. Water from each mesocosm was sampled mid-tank at $1 \mathrm{~m}$ depth by siphoning into $30 \mathrm{~L}$ carboys for dissolved organic carbon (DOC), size-fractionated particulate organic carbon (POC), phytoplankton biomass (measured from one replicate per treatment only), chlorophyll $a,{ }^{13} \mathrm{C}$ content of carbon pools (DIC, size-fractionated POC), ciliate and zooplankton abundance, bacterial biomass and production on day $1,2,3$, $4,6,8,11,14$, and 17. In addition, samples were collected for the analysis of seston fatty acid concentration and combined fatty acid-specific $\delta^{13} \mathrm{C}$ isotope biomarkers $\left(\delta^{13} \mathrm{C}-\mathrm{FA}\right)$ over the experimental duration. Plankton was sampled following the gentle stirring of the mesocosms in order to disperse organisms equally. For copepods, 10-20 L samples were repeatedly taken with a $5 \mathrm{~L}$ polycarbonate beaker. Appendicularians were sampled daily by gentle immersion of a $6 \mathrm{~L}$ polycarbonate beaker with no loss of appendicularians due to sloshing out from the receptacle.

Phytoplankton samples were analyzed by epifluorescence microscopy and cell volumes were calculated by approximation of simple geometrical 3D shapes and converted into cell carbon (Menden-Deuer and Lessard 2000). Appendicularians were immediately enumerated and staged by microscopy after sampling (Troedsson et al. 2013). Zooplankton (copepod) samples were concentrated on a $50 \mu \mathrm{m}$ sieve, preserved with acidic Lugol's solution and the taxonomic composition was analyzed to the lowest taxonomic level possible. Samples were generally fully analyzed (on average 180-1003 ind./ sample). Ciliate abundance was analyzed from untreated live plankton samples using two black and white FlowCAM II instruments. Data acquisition was done in autoimage-mode with a $4 \mathrm{x}$ objective. Particle size ranges were set at 15-1000 $\mu \mathrm{m}$ cell size (Calbet et al. 2014).

Analysis of samples for POC, DOC, phytoplankton FA composition, bacterial biomass and production, as well as 
analysis of stable isotope and $\delta^{13} \mathrm{C}$-FA data and a more detailed phytoplankton analysis are described in the Supporting Information text S1.

\section{Statistical analysis}

To investigate effects of temperature (T), $\mathrm{CO}_{2}(\mathrm{C})$ and addition with $O$. dioica (A) on standing stocks and rates repeatedmeasures ANOVA were used with generalized linear mixed models (GLMM) and mesocosms as a random effect. A firstorder autoregressive term was included in the GLMM to account for repeated measurement. Main effects are reported from the ANOVA outcome of the models. Effects were investigated during the phytoplankton bloom (day 3-7) and postbloom (day 11-17) periods. In addition, ANOVA was used to investigate differences across treatments for single day or averaged measurements. Statistical analyses were accomplished using the R software environment 3.0.1 (R Development Core Team 2009) and the MASS package. Complete ANOVA results are given in Supporting Information Table S1.

\section{Results and discussion}

Phytoplankton dynamics using Chl $a$ as a proxy was similar between $\mathrm{pCO}_{2}$ and appendicularia treatment manipulations with a tendency of slightly lower biomass in the latter treatments during the bloom and higher biomass during the postbloom phase at high temperature (ANOVA, $F_{(1,10)}>13.4$, $p<0.004$ ) (Fig. 2a,b, Supporting Information Fig. S2). The phytoplankton bloom was short-lived with the fastest decline in the high temperature treatments and remained at low levels during the postbloom period. Lower phytoplankton biomass during the bloom phase was mainly due to the faster decline after the peak at high temperature compared to lower temperature. Both the phytoplankton community composition, which was dominated by the diatom Skeletonema marinoi, and to a lesser extent by chlorophytes and haptophytes (Fig. 3), and their fatty acid compositions (used as a measure of food quality, Supporting Information Fig. S3), showed a similar trajectory across treatments over the experimental duration. Shifts in phytoplankton species composition as a result of high $p \mathrm{CO}_{2}$ have been observed in some studies, primarily indicating a decrease of calcifying phytoplankton that are sensitive to low $\mathrm{pH}$ (Engel et al. 2008). Shifts in community composition can cause changes in phytoplankton fatty acid compositions (Bermudez et al. 2016), which may also be affected directly by high $p \mathrm{CO}_{2}$ (Rossoll et al. 2012). Our observations support previous studies suggesting that coastal phytoplankton communities are tolerant to high $\mathrm{pCO}_{2}$ (Czerny et al. 2013; Rossoll et al. 2013). However, phytoplankton taxon-specific growth rates measured as ${ }^{13} \mathrm{C}$-DIC uptake into fatty acids revealed a significant synergistic effect of high temperature and high $p \mathrm{CO}_{2}$, especially in chlorophytes (Tukey HSD, $p<0.001$ ) (Fig. 4a). ${ }^{13} \mathrm{C}$-DIC uptake decreased at high $\mathrm{CO}_{2}$ levels in the dominant phytoplankton taxa of dinoflagellates (Tukey HSD $p<0.05)$ and chlorophytes $(p<0.002)$, and was marginally significant in diatoms $(p<0.07)$ (Fig. $4 \mathrm{~b})$, suggesting that availability of high $\mathrm{CO}_{2}$ reduces the need to operate a costly carbon-concentration mechanism (Reinfelder 2011). These observations suggest that phytoplankton standing stocks were strongly modulated by temperature and nutrient resource limitation.

Appendicularians exhibited a strong numerical response to temperature increase in treatments with and without $O$. dioica addition and increased rapidly after 1 week and remained at consistent densities or further increased throughout the rest of the experiment. The addition of $O$. dioica resulted in significantly higher appendicularian abundance in all treatments during both the bloom $\left(F_{(1,12)}=33.1\right.$, $p<0.001)$ and postbloom $\left(F_{(1,12)}=5.0, p=0.04\right)$ period compared to treatments with no $O$. dioica addition. Total appendicularian abundance increased approximately 10 fold at high temperature compared to ambient conditions of the respective treatments during the postbloom period $\left(F_{(1,12)}=6.9, p=0.02\right)$ and was not affected by high $p \mathrm{CO}_{2}$ $(p>0.5)$ (Fig. 2c,d). O. dioica reached densities of 10 ind. $\mathrm{L}^{-1}$ and 60 ind. $\mathrm{L}^{-1}$ in warming treatments without and with addition, respectively, and remained at low levels $(<1$ ind. $\mathrm{L}^{-1}$ ) in the low temperature treatments without addition, irrespective of $p \mathrm{CO}_{2}$ level. These observations are consistent with appendicularian response to elevated temperature and increased $p \mathrm{CO}_{2}$ (Troedsson et al. 2013), and predictions that consumers are expected to gain an advantage with climate warming because increased temperature speeds up biological processes of heterotrophs compared to autotrophs (Hansson et al. 2012; Gilbert et al. 2014). In particular, consumers with high growth rates, such as appendicularians (Stibor et al. 2004), can be expected to respond quickly to shortterm temperature increase. Moreover, this study shows that appendicularians tolerate elevated $\mathrm{CO}_{2}$ levels and supports results from a previous experiment (Troedsson et al. 2013), which did not allow a differentiation of the response due to high $\mathrm{pH}$ increased up to 8.4 in the ambient treatments during the stimulated phytoplankton bloom (Troedsson et al. 2013). As a result of their tolerance to low $\mathrm{pH}$ as confirmed in this study, appendicularians are consequently expected to be an increasingly important zooplankton component of marine food webs in a future warmer and more acidic ocean.

In contrast to appendicularians, temperature, and $\mathrm{pCO}_{2}$ addition did not affect calanoid copepods, the dominant copepods (Fig. 2e,f) or rotifer abundance (Dutz et al. 2013), although at higher temperature, the peak of rotifer abundance appeared earlier. Calanoid copepod abundance continuously increased after the phytoplankton bloom until the end of the experiment. The addition of $O$. dioica reduced copepod abundance (dominated by Temora longicornis) during the postbloom period $\left(F_{(1,10)}=4.8, p=0.05\right)$, but not during the bloom period, suggesting that these organisms compete for resources. Ciliate abundance, another dominant grazer 
a

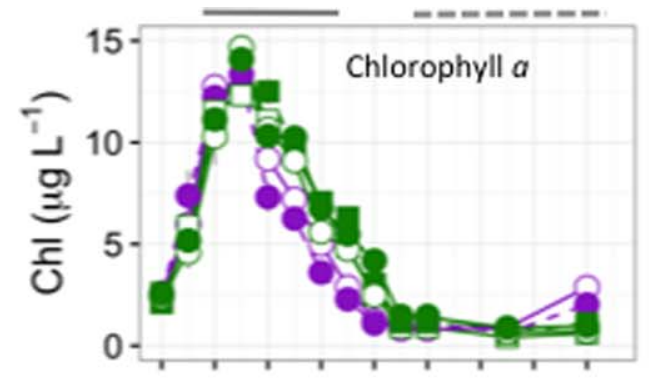

C

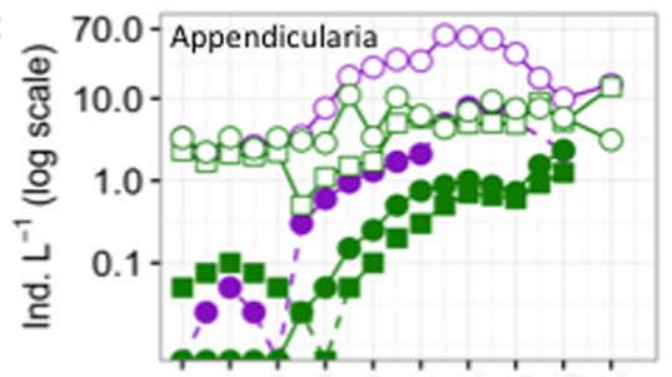

e

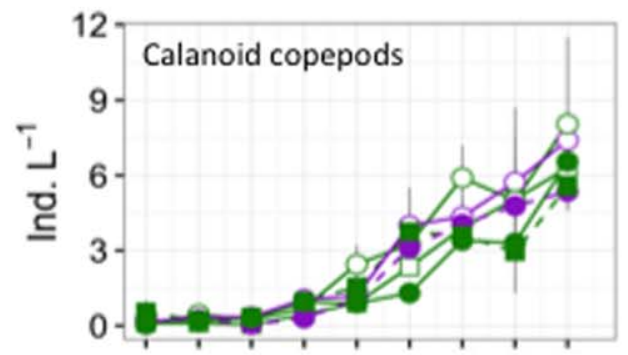

g

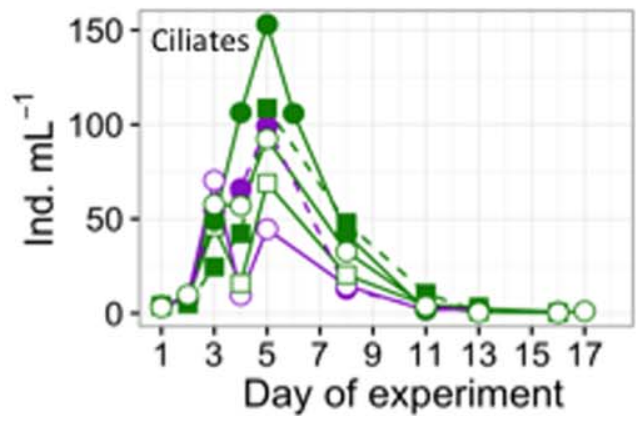

Treatment $\quad b$

TI-Cl-A-

Tl-Cl-A+

Tl-Ch-A-

TI-Ch-A+

Th-Ch-ATh-Ch-A+
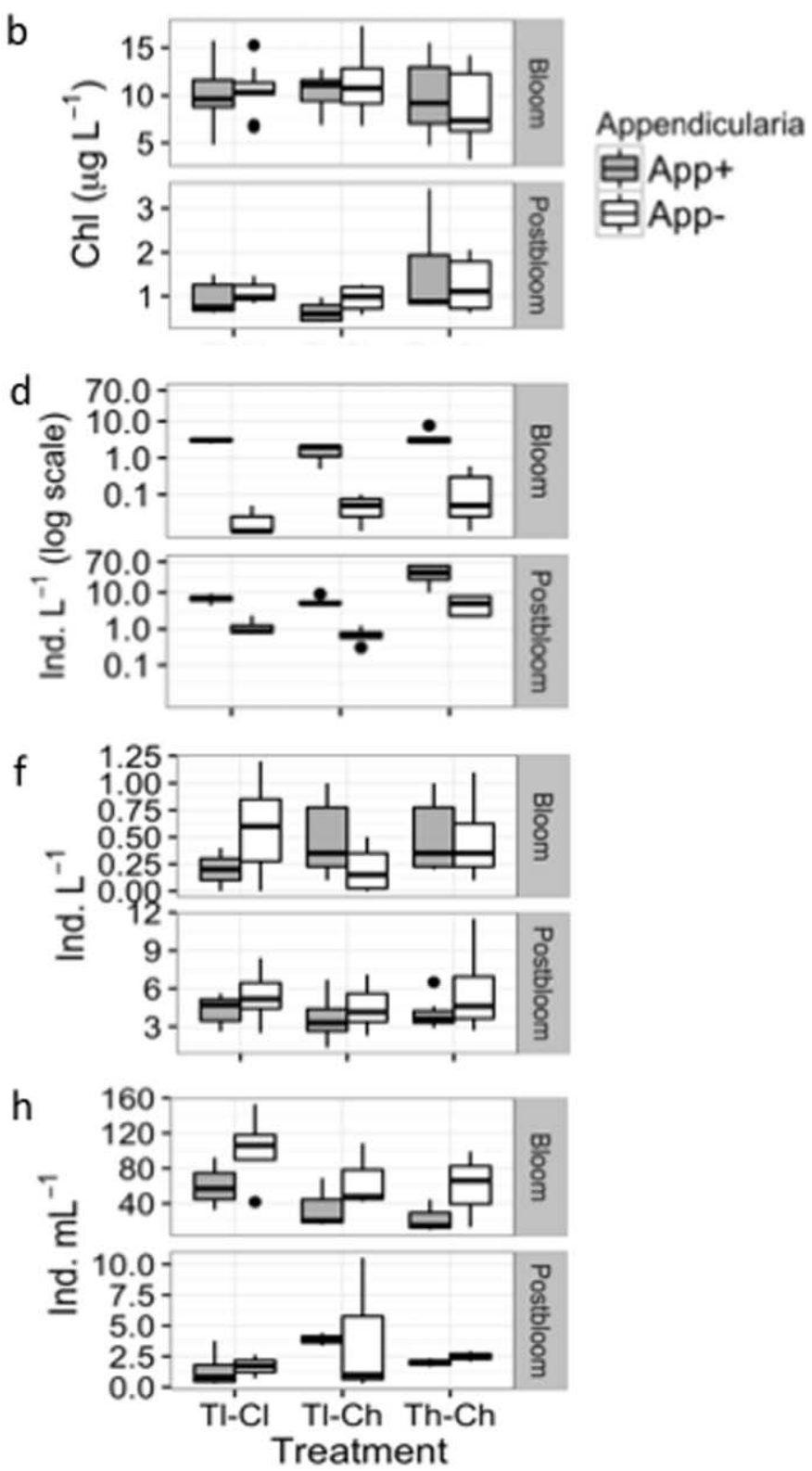

Fig. 2. Plankton temporal dynamics during the experimental period (left panels) and corresponding boxplots (right panels) during the bloom and post-bloom period across treatment manipulations. (a, b) Phytoplankton biomass shown as Chl a concentration; the bloom (day 3-7, horizontal line) and postbloom (day 11-17, dashed line) periods are highlighted; (c, d) Appendicularian abundance; (e, f) Calanoid copepod abundance; and (g, h) ciliate abundance. Treatment manipulations: $\mathrm{Tl}$ and $\mathrm{Th}=\mathrm{low}$ and high temperature, $\mathrm{Cl}$ and $\mathrm{Ch}=\mathrm{low}$ and high $p \mathrm{CO}_{2}, \mathrm{~A}-$ and $\mathrm{A}+=\mathrm{absence}$ and presence of appendicularia additions, respectively. Box plot bars represent $25^{\text {th }}, 50^{\text {th }}$, and $75^{\text {th }}$ percentiles, whiskers the $10^{\text {th }}$ and $90^{\text {th }}$ percentiles and points show outliers.

present in our study, peaked during the phytoplankton bloom and densities declined rapidly in all treatments with no significant differences between all treatments after the bloom $(p>0.12)$ (Fig. 2g,h). Ciliates reached highest densities at low $p \mathrm{CO}_{2}\left(F_{(1,10)}=5.41, p=0.04\right)$ and were more abundant in the treatments that did not receive added appendicularians $\left(F_{(1,10)}=9.43, p=0.01\right)$ during the bloom period. Higher ciliate densities in treatments without $O$. dioica addition and low $p \mathrm{CO}_{2}$ likely indicate interspecific competition for food. Appendicularians can also feed on ciliates (Lombard et al. 2010) and can thereby directly affect their abundance. This suggests that appendicularians were able to outcompete protozoans for food resources as both organisms prey on similar size ranges (Gorsky and Fenaux 1998). Furthermore, appendicularians likely impacted copepods by reducing ciliate abundance, a dominant prey for copepods. 


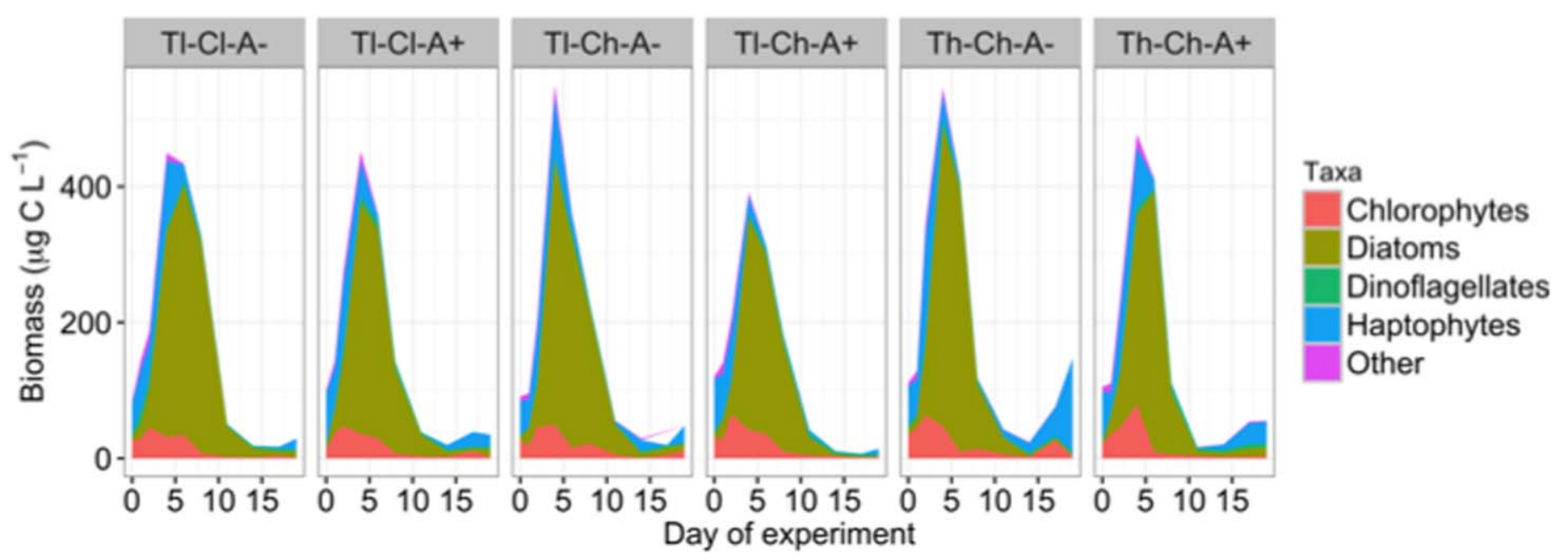

Fig. 3. Phytoplankton dynamics (in carbon biomass) of major taxonomic groups across treatments over the duration of the experiment. The phytoplankton bloom was short-lived and the temporal development was similar between mesocosms with the fastest decline in the high temperature treatments. Treatments: Temperature-low ( $\mathrm{Tl})$, temperature-high $(\mathrm{Th}), \mathrm{CO}_{2}$-low $(\mathrm{Cl}), \mathrm{CO}_{2}$-high $(\mathrm{Ch})$, without $\mathrm{O}$. dioica $(\mathrm{A}-)$ and with $\mathrm{O}$. dioica $(\mathrm{A}-)$ addition.
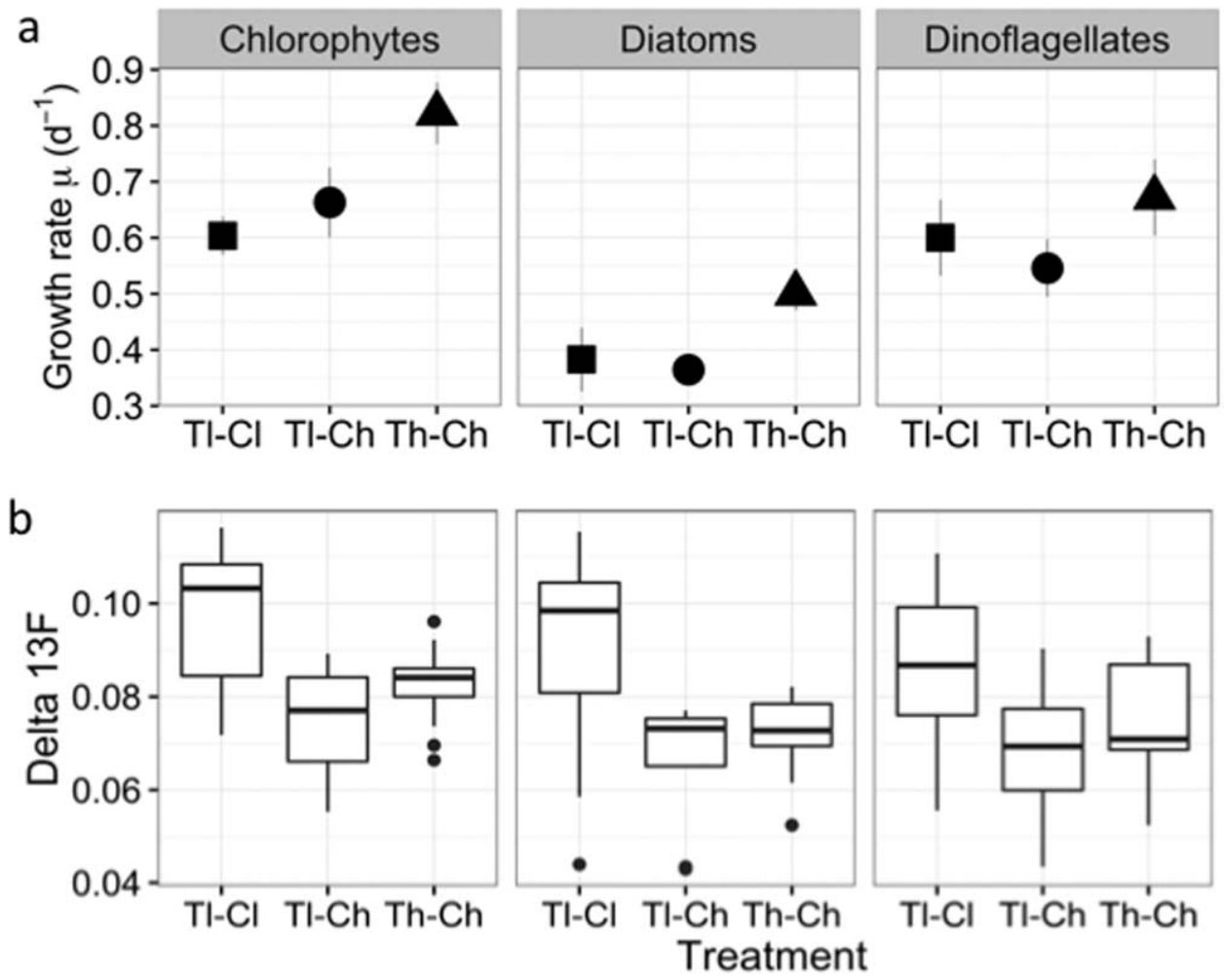

Fig. 4. Phytoplankton growth rates and carbon uptake. (a) Growth rates measured as ${ }^{13} \mathrm{C}$-DIC uptake into phospholipid-derived fatty acids for diatoms, dinophyceae, and chlorophytes during the bloom initiation, separated by temperature and $p \mathrm{CO}_{2}$ treatment manipulation, and (b) phytoplankton ${ }^{13} \mathrm{C}$-DIC uptake into phospholipid derived fatty acids of taxon-specific phytoplankton groups measured as the fractional isotope value difference before and after labeling during the bloom initiation (Delta 13F).

Increasing appendicularian abundance also affected the size distribution of POC. This was particularly apparent during the postbloom phase of the experiment when appendicularian abundance was highest (Fig. 5). During this time period, $O$. dioica addition had a significant positive effect on the micro-size fraction $>10 \mu \mathrm{m} \quad\left(F_{(1,10)}=5.1\right.$, 

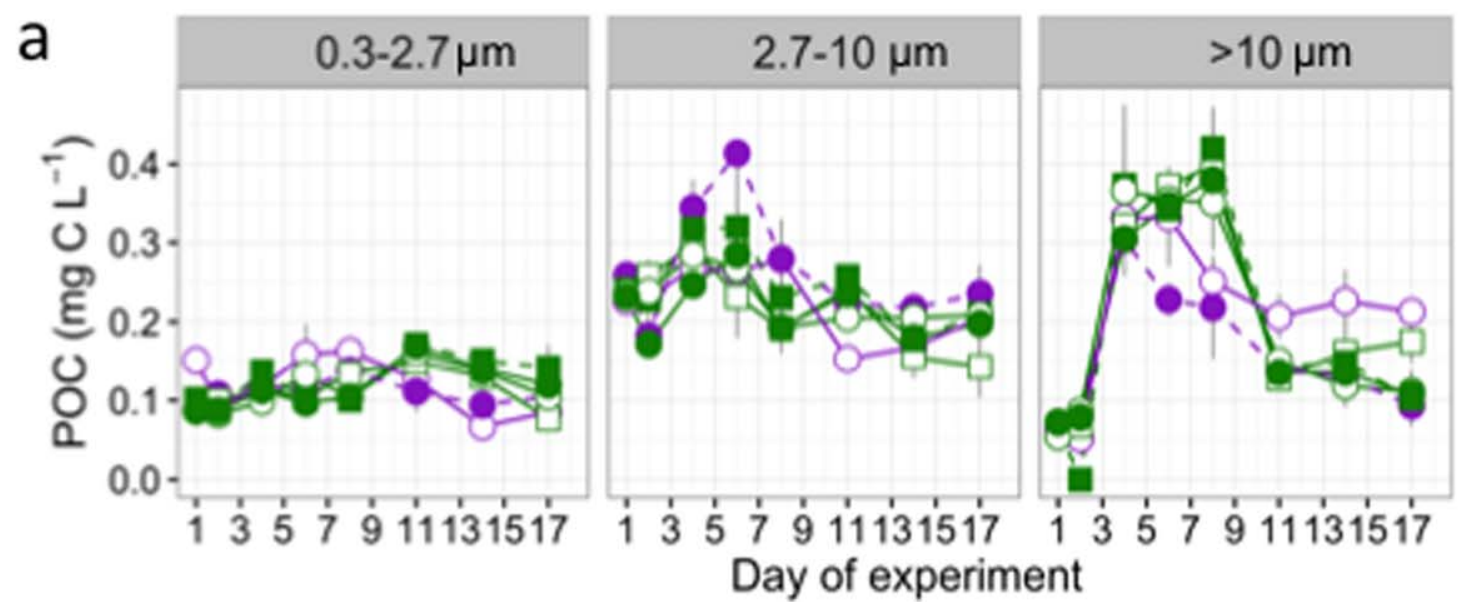

\section{Treatment \\ TI-Cl-A- \\ Tl-Cl-A+ \\ TI-Ch-A- \\ TI-Ch-A+ \\ Th-Ch-A- \\ Th-Ch-A+}
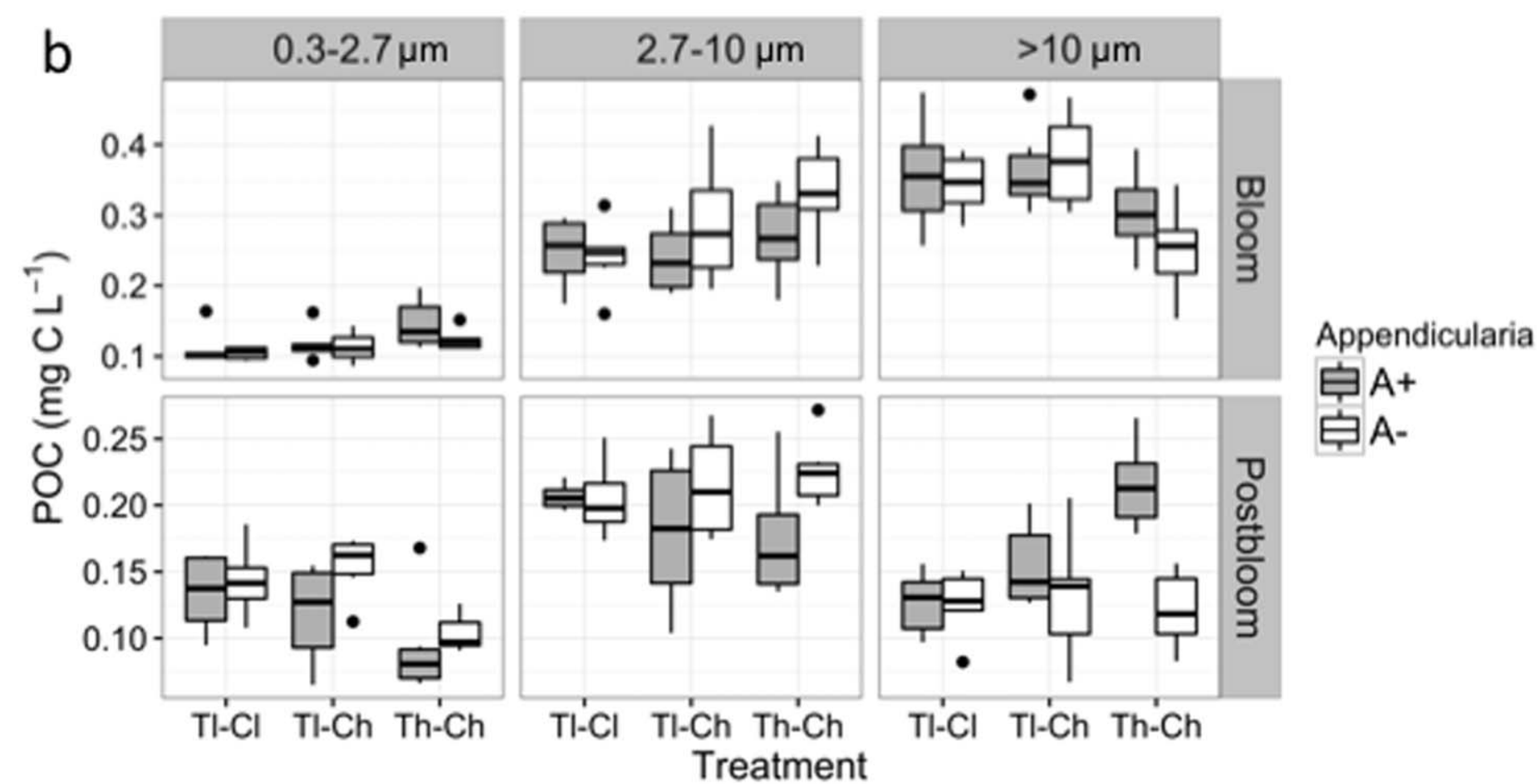

Fig. 5. Impacts of appendicularians on dynamics of particulate organic carbon (POC). (a) Temporal dynamics of size-fractionated POC and (b) box plots of POC during the phytoplankton bloom (day 3-7) and post-bloom (day 11-17) periods in the absence and presence of appendicularian additions in the different mesocosm treatments. The micro- and nano-size fractions of POC dominated during the bloom period while the picoplanktonsize fraction was low throughout the experiment. See Fig. 2 for treatment abbreviation and box plot description.

$p=0.047)$, whereas the nano-size fraction of $2.7-10 \mu \mathrm{m}$ showed opposite effects and a tendency toward reduced values with $O$. dioica addition $\left(F_{(1,10)}=3.5, p=0.09\right)$. Similarly, the pico-size fraction $<2.7 \mu \mathrm{m}$ was significantly lower at high temperature during the bloom $\left(F_{(1,10)}=6.7, p=0.03\right)$ and postbloom phases $\left(F_{(1,10)}=16.1, p=0.002\right)$, likely due to increased appendicularian grazing. Appendicularians are known to ingest small particles of the picoplankton $(<2 \mu \mathrm{m})$ size fraction (Gorsky et al. 1999; Sommer and Stibor 2002), and consequently, increases in appendicularian abundance can shift the phytoplankton community to larger cells. Shift in phytoplankton communities toward larger cells and concentration of small-sized phytoplankton in discarded appendicularian houses and their fecal pellets, likely contribute to fast-sinking particle aggregates (Turner 2015). Even though, sedimentation was not measured in our experiment, it can be assumed that both of these processes enhance the vertical particle flux contributing to marine snow in the presence of appendicularians. In fact, appendicularian houses can contribute up to $83 \%$ of vertical POC flux with most values 

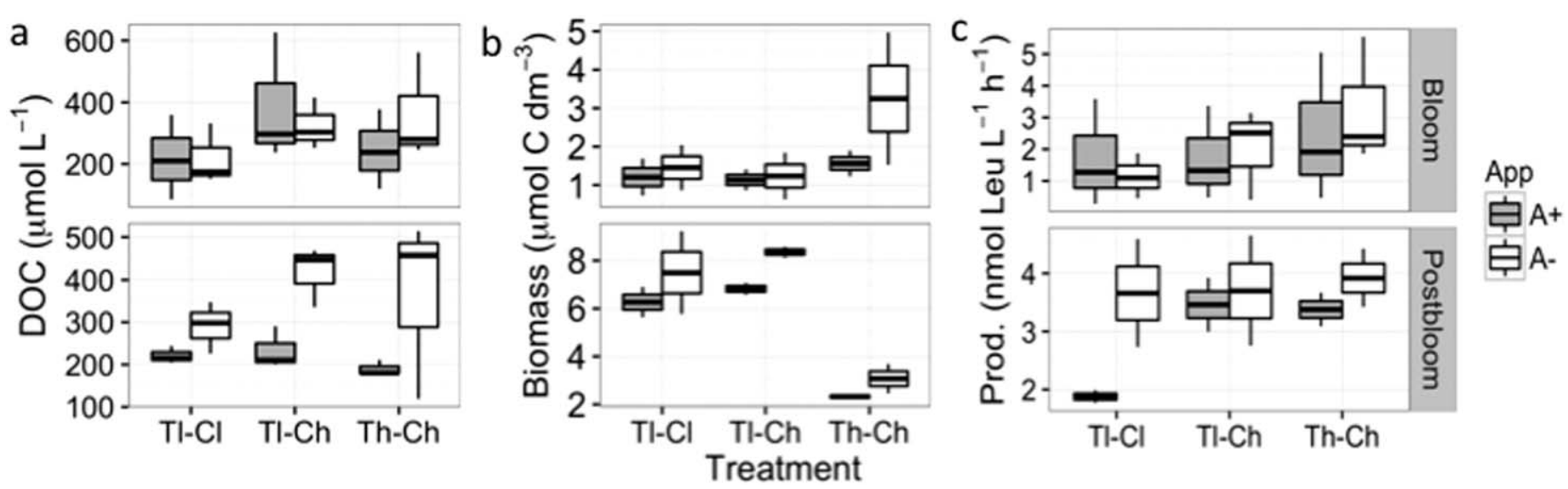

Fig. 6. Dissolved organic carbon (DOC), bacterial biomass, and bacterial production during the experiment. (a) Boxplots of DOC concentration, (b) bacterial biomass, and (c) bacterial production during the bloom (day 3-7) and post-bloom periods (day 11-17), separated by appendicularian treatment. See Fig. 2 for treatment abbreviation and box plot descriptions.

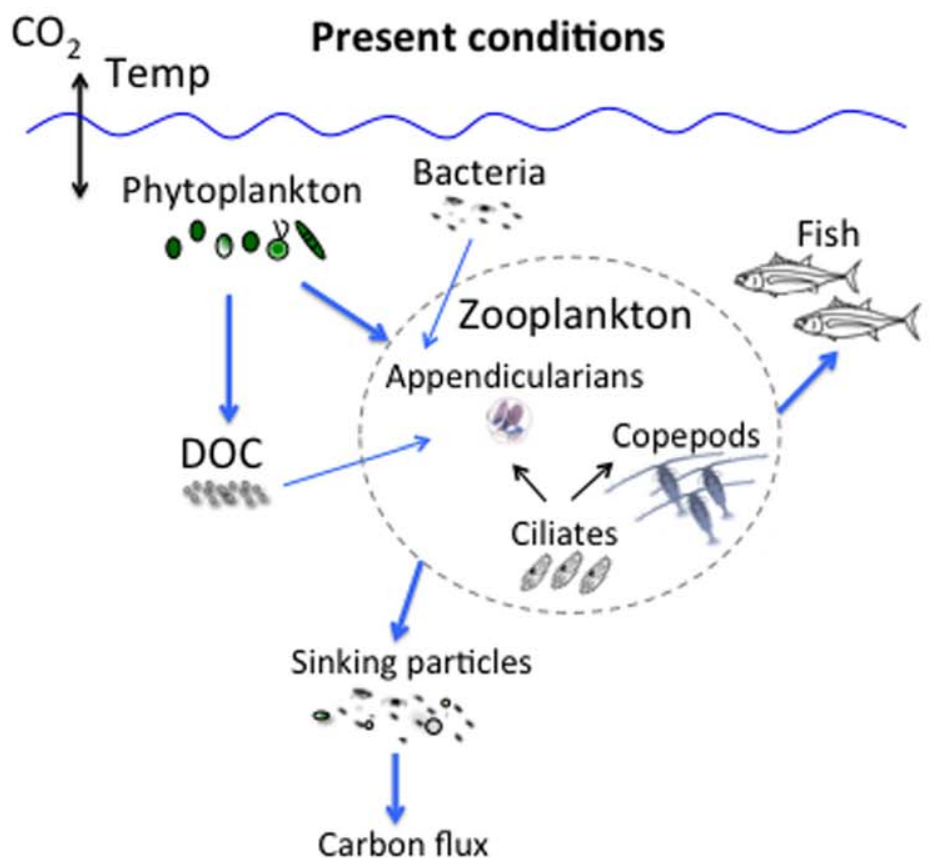

Higher temperature and $\mathrm{CO}_{2}$
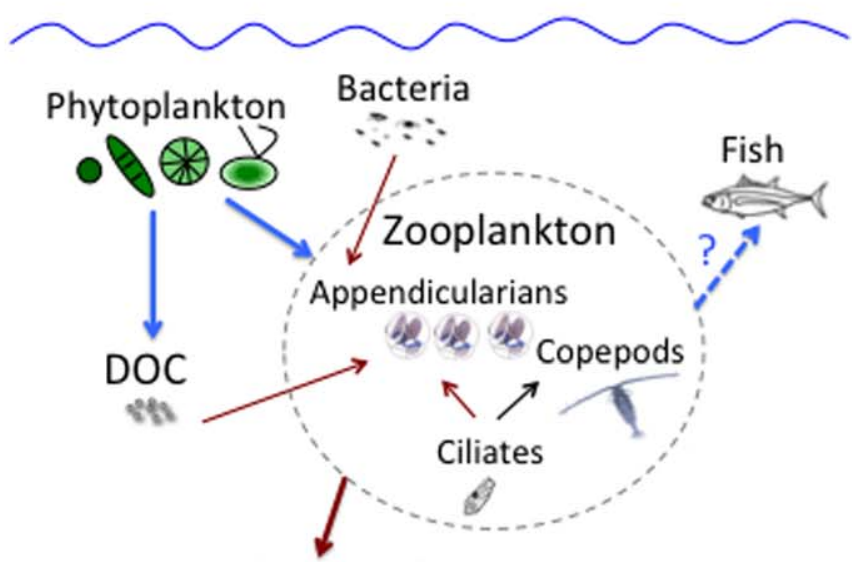

Sinking particles

Fig. 7. Schematic model illustrating carbon (C) pools and fluxes within the planktonic food web at present day (left panel) and higher temperature and $\mathrm{CO}_{2}$ levels (right panel) that favor appendicularian growth. Arrow size indicates relative magnitude of $\mathrm{C}$ fluxes between the pools, and the number of pool symbols, the relative $\mathrm{C}$ pool sizes. Blue arrows indicate trophic links, red arrows indicate stimulated fluxes and blue dashed arrows, unknown effects at elevated $\mathrm{CO}_{2}$ and temperature. Some of the pools and fluxes were not measured directly and inferred from other measured parameters.

from 28-39\% (Alldredge 2005; Dagg and Brown 2005; Deibel et al. 2005).

The effect of appendicularians on carbon cycling was also apparent based on the dynamics of DOC concentration and bacterial biomass. Significantly reduced DOC concentrations $\left(F_{(1,10)}=7.4, p=0.02\right)$ were observed in treatments with high appendicularian abundance during the postbloom period, i.e., at their highest abundance (Fig. 6).
Bacterial biomass was reduced by more than twofold at high temperature during the post-bloom period when appendicularian abundance was at its maximum $\left(F_{(1,10)}=30.3, \quad p<0.01\right)$, and likely driven by the high appendicularian abundance. Bacterial production was slightly higher at elevated temperature $\left(F_{(1,10)}=4.75, p=0.05\right)$ during the bloom period (Fig. 6), but was not significantly affected by appendicularian addition. 
Appendicularians can retain particles as small as $0.1 \mu \mathrm{m}$ in their external filtration houses (Flood and Deibel 1998) and thus consume particles in the DOC $(<0.8 \mu \mathrm{m})$ and bacteria size range. Consumption of picoplankton-sized particles is most likely the reason for both reduced DOC and bacterial biomass in treatments with high appendicularian abundances. Nevertheless, DOC concentration was relatively high in appendicularian addition treatments and phytoplankton growth remained positive even during the post-bloom phase, both of which are likely reasons for the maintenance of high appendicularian abundances. In addition, peak appendicularian abundance occurred immediately post spawn and high density was retained during the non-feeding larval stage and early feeding stages of animals when they were small, resulting in reduced clearance rate compared to older, larger animals with higher clearance rates (Selander and Tiselius 2003). Indeed, as animals began to attain larger sizes, their abundances started to decline, suggesting a mismatch between their clearance rate capacity and available particles.

Our observations with low DOC concentrations and low bacterial biomass in treatments with high appendicularian abundance differ from earlier findings indicating that jellyfish can produce copious amounts of labile C-rich DOC fueling microbial activity (Condon et al. 2011). The discrepancy between these studies may be related to differences in the excretion strategies of the taxonomic groups involved and the experimental scale and duration. Previous studies that report increased DOC release from jellyfish involved ctenophores and medusa species that release assimilated material via excretion and mucus production (Condon et al. 2011). Moreover, these studies measured release of assimilated material as DOC in small volume individual incubations within $24 \mathrm{~h}$, neglecting food web processes. In comparison, we measured DOC over an extended time period under conditions simulating natural ones more accurately, and allowing carbon mechanism processes to adapt and respond accordingly. Further, O. dioica houses are discarded up to 6 times per day (Troedsson et al. 2009) and can be as high as 27 houses per day for other appendicularian species (Sato et al. 2003) and contribute substantially to high POC export rates (Alldredge 2005; Dagg and Brown 2005; Deibel et al. 2005), similar to dead fast sinking ctenophores and medusa species (Lebrato et al. 2013).

While copepods are an important prey for fish, the significance of appendicularians for fish production is largely unknown. Some fish larvae consume large amounts of appendicularians, such as early-stage Plaice fish (Shelbourne 1962). Appendicularians have an average caloric density for zooplankton and are nutritionally rich in fatty acids and proteins (Alldredge 1976; Fyhn et al. 2005; Troedsson et al. 2005), qualities that make them a prey of high nutritional value for fish larvae. In addition, high abundances, wide distribution patterns, fast growth rates, and appropriate size for fish larvae make them potentially an import prey for many early-stage fish larvae and other predators. However, the extent of their role as a potential prey for fish needs to be better evaluated.

Our study shows that gelatinous appendicularian zooplankton thrive under warmer temperature and benefit from low $\mathrm{pH}$ levels. These organisms remove DOC, bacteria and small-sized particles with their filter-feeding houses, resulting in increased carbon removal from the water column, and efficiently convert primary production into particulate gelatinous biomass (Fig. 7). Increased gelatinous appendicularian biomass could benefit organisms that consume these prey items. Alternatively, high abundance of appendicularians could reduce trophic transfer to fish via competition and consumption of microbial prey and increased vertical carbon transport by aggregating small particles (Sato et al. 2003). An overall interpretation is that appendicularians may alter the direction of direct climate effects by enhancing particle aggregation, and thereby increasing vertical carbon transport (Fig. 7).

\section{Conclusions}

Our study highlights the importance of understanding consumer responses to climate change and their feedbacks on ecosystem functioning at ecosystem scale because species interactions alter the food web translation of direct climate effects. Generally, ocean warming is expected to accelerate biological processes, and consumers mediate ecosystem responses to increasing atmospheric $\mathrm{CO}_{2}$, thus contributing to future restructuring of pelagic ecosystems and biogeochemical cycling. Our study demonstrated clear temperature effects on gelatinous zooplankton consumers that exhibited tolerance to elevated $\mathrm{CO}_{2}$ levels. Mediated by the response of appendicularians, primary producers and carbon cycling were impacted indirectly through complex species interactions. Gelatinous zooplankton favored by climate warming and ocean acidification will impact top down control of the microbial loop. This will likely lead to increased sedimentation of organic material from fast-sinking discarded houses and fecal pellets. This is an important component of the biological pump and may contribute to $\mathrm{CO}_{2}$ removal from the atmosphere, mitigating anthropogenic increase in greenhouse gases (Falkowski and Oliver 2007). However, according to this study, dominance of appendicularians may decrease carbon available to copepods by converting microbial biomass into gelatinous biomass, with significant environmental and possibly, fisheries implications.

Author Contribution Statement. All authors carried out the mesocosm experiment and lab analysis, MW, JMB, SAB, JCN, EMT designed the study, MW wrote the manuscript with inputs from EMT; all authors commented on the manuscript and gave final approval for publication. 


\section{References}

Alldredge, A. L. 1976. Field behavior and adaptive strategies of appendicularians (Chordata: Tunicata). Mar. Biol. 38: 29-39. doi:10.1007/BF00391483

Alldredge, A. L. 2000. The impact of appendicularian grazing on natural food concentrations in situ. Limnol. Oceanogr. 26: 247-257. doi:10.4319/lo.1981.26.2.0247

Alldredge, A. L. 2005. The contribution of discarded appendicularian houses to the flux of particulate organic carbon from oceanic surface waters, p. 315-332. In G. Gorsky, M. J. Youngbluth, and D. Deibel [eds.], Response of marine ecosystems to global change: Ecological impact of appendicularians. Editions Scientifiques, Paris.

Bermudez, R. J., U. Riebesell, A. Larsen, and M. Winder. 2016. Ocean acidification reduces transfer of essential biomolecules in a natural plankton community. Sci. Rep. 6: 27749. doi:10.1038/srep27749

Calbet, A., and others. 2014. Future climate scenarios for a coastal productive planktonic food web resulting in microplankton phenology changes and decreased trophic transfer efficiency. PLoS One 9: e94388. doi:10.1371/ journal.pone.0094388

Condon, R. H., D. K. Steinberga, P. A. del Giorgioc, T. C. Bouvierd, D. A. Bronka, W. M. Grahamb, and H. W. Ducklowe. 2011. Jellyfish blooms result in a major microbial respiratory sink of carbon in marine systems. Proc Natl Acad Sci USA. 108: 10225-10230. doi:10.1073/pnas.1015782108

Condon, R. H., and others. 2013. Recurrent jellyfish blooms are a consequence of global oscillations. Proc Natl Acad Sci USA. 110: 1000-1005. doi:10.1073/pnas.1210920110

Czerny, J., and others. 2013. Implications of elevated $\mathrm{CO}_{2}$ on pelagic carbon fluxes in an Arctic mesocosm study an elemental mass balance approach. Biogeosciences 10: 3109-3125. doi:10.5194/bg-10-3109-2013

Dagg, M. J., and S. L. Brown. 2005. The potential contribution of fecal pellets from the larvacean Oikopleura dioica to vertical flux of carbon in a river domianted coastal margin, p. 299-213. In G. Gorsky, M. J. Youngbluth, and D. Deibel [eds.], Response of marine ecosystems to global change: Ecological impact of appendicularians. Editions Scientifiques, Paris.

Deibel, D. 1998. The abundance, distribution, and ecological impact of doliolids, p. 171-186. In Q. Bone [ed.], The biology of pelagic tunicates. Oxford Univ. Press.

Deibel, D., P. A. Saunders, J. L. Acuna, A. B. Bochdansky, N. Shiga, and R. B. Rivkin. 2005. The role of appendicularian tunicates in the biogenic carbon cycle of three arctic polynyas, p. 333-363. In G. Gorsky, M. J. Youngbluth, D. Deibel [eds.], Response of marine ecosystems to global change: Ecological impact of appendicularians. Editions Scientifiques, Paris.

Dutz, J., L. Samchyshyna, A. F. Sazhin, C. Troedsson, J. M. Bouquet, and E. M. Thompson. 2013. Effects of ocean acidification and temperature on marine zooplakton: A mesocosm study. Abstract presented at ASLO meeting, New Orleans.

Engel, A., K. G. Schulz, U. Riebesell, R. Bellerby, B. Delille, and M. Schartau. 2008. Effects of $\mathrm{CO}_{2}$ on particle size distribution and phytoplankton abundance during a mesocosm bloom experiment (PeECE II). Biogeosciences 5: 509-521. doi:10.5194/bg-5-509-2008

Estes, J. A., and others. 2011. Trophic downgrading of planet Earth. Science 333: 301-306. doi:10.1126/science.1205106

Falkowski, P. G., and M. J. Oliver. 2007. Mix and match: How climate selects phytoplankton. Nat. Rev. Microbiol. 5: 813-819. doi:10.1038/nrmicro1751

Flood, P. R., and D. Deibel. 1998. The appendicularian house, p. 105-124. In Q. Bone [ed.], The biology of pelagic tunicates. Oxford Univ. Press.

Fyhn, H. J., O. Mjaavatten, J. O. Larsen, M. S. Evjen, and G. Gorsky. 2005. Amino acid and fatty acid contents in the appendicularian (Oikopleura dioica) fed micro algae, p. 179-195. In G. Gorsky, M. J. Youngbluth, and D. Deibel [eds.], Response of marine ecosystems to global change: Ecological impact of appendicularians. Editions Scientifiques, Paris.

Gilbert, B., and others. 2014. A bioenergetic framework for the temperature dependence of trophic interactions. Ecol. Lett. 17: 902-914. doi:10.1111/ele.12307

Gorsky, G., and R. Fenaux. 1998. The role of Appendicularia in marine food webs, p. 161-169. In Q. Bone [ed.] The biology of pelagic tunicates. Oxford Univ. Press.

Gorsky, M., M. J. Chretiennot-Dinet, J. Blanchot, and J. Palazzoli. 1999. Picoplankton and nanoplankton aggregation by appendicularians: Fecal pellet contents of Megalocercus huxleyi in the equatorial Pacific. J. Geophys. Res. 104: 3381-3390. doi:10.1029/98JC01850

Hansson, L. A., and others. 2012. Food-chain length alters community responses to global change in aquatic systems. Nat. Clim. Chang. 3: 228-233. doi:10.1038/nclimate1689

IPCC. 2014. Climate change 2014: Impacts, adaptation and vulnerability, p. 1-32. Cambridge Univ. Press.

Lebrato, M., P. de Jesus Mendes, D. K. Steinberg, J. E. Cartes, B. M. Jones, L. M. Birsa, R. Benavides, and A. Oschlies. 2013. Jelly biomass sinking speed reveals a fast carbon export mechanism. Limnol. Oceanogr. 58: 1113-1122. doi:10.4319/1o.2013.58.3.1113

Lombard, F., D. Eloire, A. Gobet, L. Stemmann, J. R. Dolan, A. Sciandra, and G. Gorsky. 2010. Experimental and modeling evidence of appendicularian-ciliate interactions. Limnol. Oceanogr. 55: 77-90. doi:10.4319/lo.2010.55.1.0077

Menden-Deuer, S., and E. J. Lessard. 2000. Carbon to volume relationships for dinoflagellates, diatoms, and other protist plankton. Limnol. Oceanogr. 45: 569-579. doi: 10.4319/lo.2000.45.3.0569

R Development Core Team. 2009. R: A language and environment for statistical computing. Vienna: R Foundation 
for Statistical Computing. ISBN 3-900051-07-0. Available from http://www.r-project.org/

Reinfelder, J. R. 2011. Carbon concentrating mechanisms in eukaryotic marine phytoplankton. Ann. Rev. Mar. Sci. 3: 291-315. doi:10.1146/annurev-marine-120709-142720

Richardson, A. J., A. Bakun, G. C. Hays, and M. J. Gibbons. 2009. The jellyfish joyride: Causes, consequences and management responses to a more gelatinous future. Trends Ecol. Evol. 24: 312-322. doi:10.1016/j.tree.2009.01.010

Riebesell, U., and J. P. Gattuso. 2015. Lessons learned from ocean acidification research. Nat. Clim. Chang. 5: 12-14. doi:10.1038/nclimate2456

Rossoll, D., R. Bermúdez, H. Hauss, K. G. Schulz, U. Riebesell, U. Sommer, and M. Winder. 2012. Ocean acidificationinduced food quality deterioration constrains trophic transfer. PLoS One 7: e34737. doi:10.1371/journal.pone.0034737

Rossoll, D., U. Sommer, and M. Winder. 2013. Community interactions dampen acidification effects in a coastal plankton system. Mar. Ecol. Prog. Ser. 486: 37-46. doi: 10.3354/meps10352

Sato, R., Y. Tanaka, and T. Ishimaru. 2003. Species-specific house productivity of appendicularians. Mar. Ecol. Prog. Ser. 259: 163-172. doi: $10.3354 /$ meps 259163

Selander, E., and P. Tiselius. 2003. Effects of food concentration on the behaviour of Oikopleura dioica. Mar. Biol. 142: 263-270. doi:10.1007/s00227-002-0949-8

Shelbourne, J. E. 1962. A predator-prey size relationship for Plaice larvae feeding on Oikopleura. J. Mar. Biol. Assoc. U. K. 42: 243-252. doi:10.1017/S0025315400001326

Sommer, U., and H. Stibor. 2002. Copepoda - Cladocera Tunicata: The role of three major mesozooplankton groups in pelagic food webs. Ecol. Res. 17: 161-174. doi: 10.1046/j.1440-1703.2002.00476.x

Stemmann, L., and others. 2008. Global zoogeography of fragile macrozooplankton in the upper $100-1000 \mathrm{~m}$ inferred from the underwater video profiler. ICES J. Mar. Sci. 65: 433-442. doi:10.1093/icesjms/fsn010

Stibor, H., O. Vadstein, B. Lippert, W. Roederer, and Y. Olsen. 2004. Calanoid copepods and nutrient enrichment determine population dynamics of the appendicularian Oikopleura dioica: A mesocosm experiment. Mar. Ecol. Prog. Ser. 270: 209-215. doi:10.3354/meps270209

Stukel, M. R., M. D. Ohman, C. R. Benitez-Nelson, and M. R. Landry. 2013. Contributions of mesozooplankton to vertical carbon export in a coastal upwelling system. Mar. Ecol. Prog. Ser. 491: 47-65. doi:10.3354/meps10453
Troedsson, C., O. Grahl-Nielsen, and E. M. Thompson. 2005. Variable fatty acid composition of the pelagic appendicularian Oikopleura dioica in response to dietary quality and quantity. Mar. Ecol. Prog. Ser. 289: 165-175. doi:10.3354/ meps 289165

Troedsson, C., J. M. Bouquet, R. Skinnes, J. L. Acuna, K. Zech, M. E. Frischer, and E. M. Thompson. 2009. Regulation of filter-feeding house components in response to varying food regimes in the appendicularian, Oikopleura dioica. J. Plankton Res. 31: 1453-1463. doi:10.1093/plankt/fbp085

Troedsson, C., and others. 2013. Effects of ocean acidification, temperature and nutrient regimes on the appendicularian Oikopleura dioica: A mesocosm study. Mar. Biol. 160: 2175-2187. doi:10.1007/s00227-012-2137-9

Turner, J. T. 2015. Zooplankton fecal pellets, marine snow, phytodetritus and the ocean's biological pump. Prog. Oceanogr. 130: 205-248. doi:10.1016/j.pocean.2014.08.005

Vargas, C. A., and others. 2002. Importance of copepods versus appendicularians in vertical carbon fluxes in a Swedish fjord. Mar. Ecol. Prog. Ser. 241: 125-138. doi:10.3354/ meps 241125

\section{Acknowledgments}

We thank, A. Jacobsen and P. Simonelli for their logistic help and contribution, and J. Nielsen, D. Freese, D. Brennecke, and Jens Nielsen for laboratory and technical assistance. In addition, we are grateful to J. Bueno, A. Calbet, S. Ceballos, S. Dupont, J. Heuchele, S. Isari, A. Isla, M. Iversen, W. Massart, I. Magiopoulos, R. Martinez, M. Koski, A. Novac, M. Reeve, L. Samchyshyna, K. Sandnes Skaar, I. Santi, T. Tanaka, T. F. Thingstad, P. Thor, and T. M. Tsagaraki for their help during the mesocosm experiment. This work is a contribution to the German Science Foundation under the project number WI 2726/2-1 (to MW), the Marie Curie IRG grant 276917 (to MW), the US National Science Foundation grant OCE 1459293 (to MEF), the Norwegian Research Council grant NFR-HK 2024040/E40 (to EMT, MW, JCN, CT, J-MB, HHJ, AFS and MEF), the MESOAQUA-EU FP7-INFRA-2008-1, 228224 Transnational Access sub-projects CYCLE (to MW \& group members) and BIOPUMP (to EMT and group members), and the VELUX foundation grant VKR022608 (to HHJ).

\section{Conflict of Interest}

None declared.

Submitted 09 June 2016 Revised 28 October 2016; 19 December 2016 Accepted 20 December 2016 Associate editor: Thomas Anderson 